who has access to the patients' medical records to document the changes?"

A prescribing pharmacist would have to perform physical exams, as a diagnosis cannot be made from a patient's history alone, Lee adds. "You can't prescribe in isolation - prescribing is part of a total package of caring for a patient."

The Alberta chapter of the Consumers' Association of Canada has also weighed in with concerns that the change will inevitably result in accrued costs to consumers; increased fragmentation of care and decreased confidentiality.

"We seriously question a number of assumptions about the benefits of enhanced prescribing powers and anticipated uses," said spokesperson Wendy Armstrong. - Alicia Priest, Victoria

DOI:I0.I503/cmaj.060903

\section{Crisis in US emergency}

\section{departments}

$\mathrm{U}$ $S$ emergency departments (EDs) are dangerously overburdened, underfunded and unprepared to cope with mass casualties from hurricanes, pandemics or terrorist attacks, according to 3 landmark reports issued in June.

A nearly 3-year investigation by the Institute of Medicine, an independent scientific group, found a crisis in US EDs, which provide the only treatment

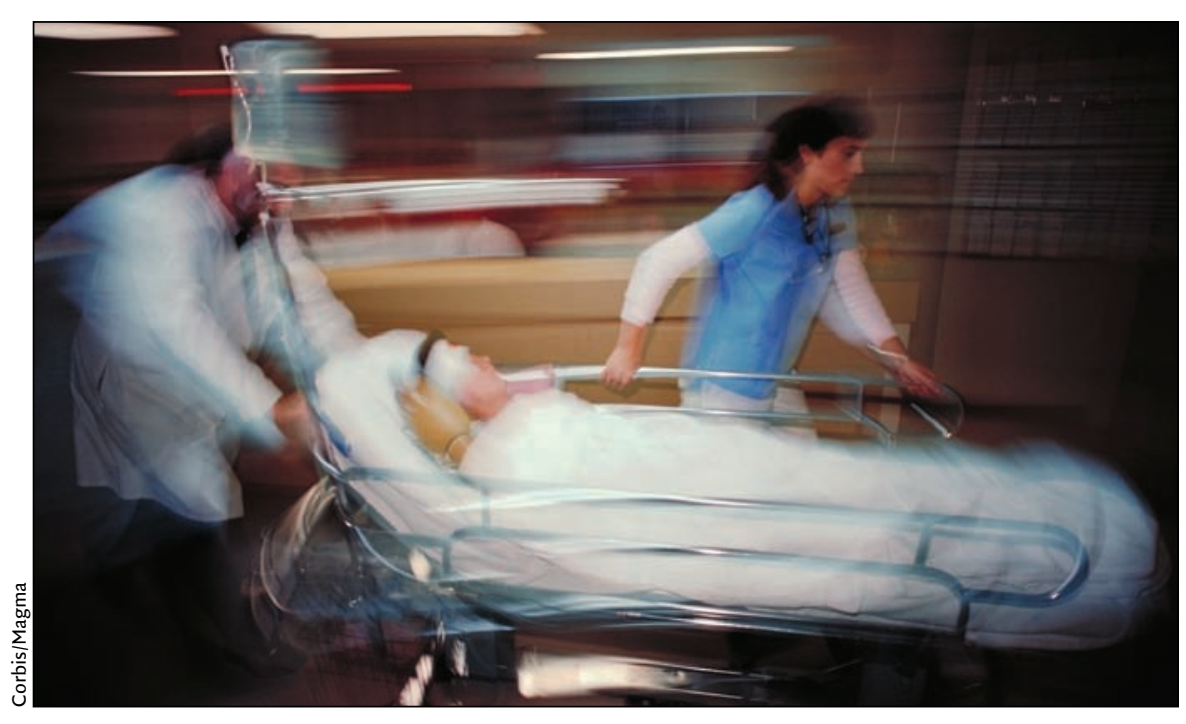

The US Institute of Medicine concludes American EDs are dangerously overburdened.

guarantee for 47 million Americans without health insurance.

The reports, collectively entitled The Future of Emergency Care, are the first extensive studies of US emergency care in the past 40 years. They present a bleak picture: a half million times a year - about once a minute ambulances carrying critically ill patients are diverted from full EDs to more distant sites. Once stabilized, patients can wait several hours, even days, on gurneys in ED hallways for inpatient beds. On-call specialists are in short supply because of the cost of malpractice insurance and the difficulty of collecting payment from uninsured patients.

Demand is surging in EDs as capacity is dropping. The number of patients treated at EDs rose $26 \%$ between 1993 and 2003. During the same period, US hospitals closed 425 EDs, partly to control spiraling costs.

A I986 law requires US EDs to stabilize anyone who shows up, regardless of their ability to pay. Only half of ED patients require life-saving intervention, according to the reports.

Inadequate resources put children, who account for $27 \%$ of all visits to EDs, at risk. Only $6 \%$ of US EDs have all the equipment needed to treat pediatric emergencies, the reports found. Half had $85 \%$ of essential supplies.

Many of the reports' key recommendations were aimed at the US Congress including:
- Allocate $\$ 50$ million to reimburse hospitals for unpaid emergency care to uninsured patients, $\$ 88$ million over 5 years for projects to test ways to promote greater coordination among emergency care providers and $\$ 37.5$ million to improve pediatric emergency services.

- Increase funding for disaster preparedness in hospitals.

- Create a lead agency in the Department of Health and Human Services to consolidate government programs dealing with emergency care.

The reports also called on hospitals to stop diverting ambulances and "boarding" patients on gurneys. It also urged EDs and responders to adopt modern information and communication technologies to improve patient flow and improve coordination between 9II dispatchers, ambulance workers and EDs.

Senate Majority Leader Bill Frist (RTenn.), a surgeon, wrote in the Philadelphia Inquirer that the problems in EDs are symptoms of larger problems and deficiencies in the US health care system. "Fixing them stands as one of the great public policy challenges of this decade," Frist wrote. J.R. Brooks, Salt Lake City, Utah

DOI:I0.1503/cmaj.06og83

\section{News @ a glance}

Cervical vaccine approved: The first-ever vaccine against cervical cancer, was approved by Health Canada in July. Gardasil (quadrivalent human papillomavirus types 6 , II, $\mathrm{I} 6$, I8, recombinant vaccine) was approved for use on females age 9 to 26 (CMAJ 2006; I75 [2]:234). Health Canada's National Advisory Committee on Immunization, which provides recommendations on vaccines, is expected to provide a recommendation on Gardasil by the end of 2006. However it is up to the provincial and territorial governments to decide whether to offer the vaccine free of charge. Gardasil is expected to cost \$135 for a full 3 -shot course over 6 months.

Hep C compensation: Eight years after its initial settlement, the federal government 
has set aside nearly \$I billion to compensate the estimated 5500 people who were infected with hepatitis $C$ from tainted blood before Jan. I, I986, and after July I, 1990. Previously, only those infected between I986 and I990 - about Io ooo people - were eligible for compensation. This second round of compensation was a key recommendation in the 1997 Justice Horace Krever Commission's report into Canada's blood system. "His reasoning was simple: all should be compensated equally because all of the victims had endured pain and suffering," said Prime Minister Stephen Harper in announcing the compensation.

Fewer smokers: Fewer than 5 million Canadians ( $19 \%$ ) aged 15 or older reported smoking daily or occasionally in 2005, reported the Canadian Tobacco Use Monitoring Survey by Statistics Canada. This is down slightly from 2004 , when $20 \%$ of the adult population smoked. For the second year, the survey found no difference in smoking prevalence among teens aged 15 to 19 (I $8 \%$ smoke daily or occasionally). Compiled by Barbara Sibbald, CMAJ

DOI:I0.1503/cmaj.060984

\section{Pulse}

\section{Canada's physician density}

\section{remains stagnant}

$\mathrm{B}$ ucking a trend that has seen most countries significantly bolster their physician ranks over the past 15 years, Canada continues to have one of the Organisation for Economic Co-operation and Development's (OECD) lowest ratios of practising doctors per Iooo population (Table I).

According to the OECD's annual health data statistics, released in late June, the average rate of physicians per rooo population across member nations (from which data could be obtained) increased to 3.I in 2004 from 2.3 in 1998 .

But while the overall average was rising by roughly $35 \%$ Canada's rate remained entirely stagnant at 2.I per 1000 population over the same time period.

"Canada is the only country not to show some kind of increase since I980," notes Canadian Institute of Health Information Vice-President Jean-Marie Berthelot.

The 2.I rate placed Canada in 26th place in the rankings of countries by physician density, well under half that of the top-ranked nation, Greece (see Table I). Only Korea, Mexico and Turkey have lower ratios (Japan might also rank lower but failed to file 2004 data).

Berthelot surmised the wide variation in physician density rates was a function of the way countries organize their health care systems. He also argued that the numbers should not be viewed in isolation. "Doctor consults per capita also vary quite significantly from I country to the next. For example, in Canada, it's 6.I doctor consults per capita, while for Japan, it's double, at I3.8, while for the US, it's much smaller at 3.9."

"We should also look at outcomes, particularly life expectancy. Canada ranked second in 2004 and 79.9 years. Japan topped the world at 8I.8 years and the US was 22nd at 77.5 years," Bertholet added. - Wayne Kondro, CMAJ

DOI:I0.1503/cmaj.060915
Table 1: Number of practising physicians per 1000 population in OECD countries

\begin{tabular}{|c|c|c|c|c|c|c|}
\hline Country & 1990 & 2000 & 2001 & 2002 & 2003 & 2004 \\
\hline Greece & 3.4 & 4.3 & 4.4 & 4.6 & 4.7 & 4.9 \\
\hline Italy & - & 4.1 & 4.3 & 4.4 & 4.1 & 4.2 \\
\hline Belgium & 3.3 & 3.9 & 3.9 & 3.9 & 4.0 & 4.0 \\
\hline Switzerland & 3.0 & 3.5 & 3.5 & 3.6 & $3.7 \mathrm{~b}$ & 3.8 \\
\hline Iceland & 2.8 & 3.4 & 3.5 & 3.6 & 3.6 & 3.6 \\
\hline Czech Republic & 2.7 & $3.4 \mathrm{~b}$ & 3.4 & 3.5 & 3.5 & 3.5 \\
\hline Netherlands & 2.5 & 3.2 & 3.3 & 3.4 & 3.5 & 3.6 \\
\hline Austria & 2.2 & 3.1 & 3.2 & 3.3 & 3.4 & 3.5 \\
\hline France & 3.1 & 3.3 & 3.3 & 3.3 & 3.4 & 3.4 \\
\hline Germany & - & 3.3 & 3.3 & 3.3 & 3.4 & 3.4 \\
\hline Norway & - & 2.9 & 3.0 & $3.4 \mathrm{~b}$ & 3.4 & 3.5 \\
\hline Portugal & 2.8 & 3.2 & 3.2 & 3.3 & 3.3 & 3.4 \\
\hline Sweden & 2.9 & 3.1 & 3.2 & 3.3 & 3.3 & - \\
\hline Hungary & 2.8 & - & - & 3.2 & 3.2 & 3.3 \\
\hline Spain & - & 3.2 & 3.1 & 2.9 & 3.2 & 3.4 \\
\hline Slovak Republic & - & 3.1 & 3.1 & 3.1 & 3.1 & 3.1 \\
\hline Denmark & 2.5 & 2.8 & 2.8 & 2.9 & 3.0 & - \\
\hline Luxembourg & 2.0 & 2.5 & 2.5 & 2.6 & 2.7 & 2.8 \\
\hline Australia & 2.2 & 2.5 & 2.5 & 2.5 & 2.6 & - \\
\hline Ireland & - & 2.2 & 2.4 & 2.4 & 2.6 & 2.8 \\
\hline Poland & 2.1 & 2.2 & 2.3 & 2.3 & 2.5 & - \\
\hline Finland & 2.0 & 2.3 & 2.3 & 2.4 & 2.4 & 2.4 \\
\hline United States & - & 2.3 & 2.3 & 2.3 & 2.4 & 2.4 \\
\hline New Zealand & 1.9 & 2.2 & 2.2 & 2.1 & 2.2 & - \\
\hline United Kingdom & $1.6 \mathrm{~b}$ & 1.9 & 2.0 & 2.1 & 2.2 & 2.3 \\
\hline Canada & 2.1 & 2.1 & 2.1 & 2.1 & 2.1 & 2.1 \\
\hline Korea & 0.8 & 1.3 & 1.4 & 1.5 & 1.6 & 1.6 \\
\hline Mexico & 1.0 & 1.5 & 1.5 & 1.5 & 1.5 & 1.6 \\
\hline Turkey & 0.9 & 1.3 & 1.3 & 1.4 & 1.4 & - \\
\hline Japan & 1.7 & 1.9 & - & 2.0 & - & 2.0 \\
\hline Average & 2.3 & 2.8 & 2.8 & 2.9 & 3.0 & 3.1 \\
\hline
\end{tabular}

Note: $\mathrm{OECD}=$ Organisation of Economic Co-operation and Development. Source: OECD Health Data, June 2006. 